\title{
Comparison of Nanocrystalline Surface Layer in Steels Formed by Air Blast and Ultrasonic Shot Peening*1,*2
}

\author{
Yoshikazu Todaka, Minoru Umemoto and Koichi Tsuchiya \\ Department of Production Systems Engineering, Toyohashi University of Technology, Toyohashi 441-8580, Japan
}

\begin{abstract}
Surface nanocrystallization in various steels by shot peening (both air blast (ABSP) and ultrasonic (USSP)) was investigated. In all the shot-peened specimens, the equiaxed nanocrystals with grain size of several $10 \mathrm{~nm}$ were observed at the surface regions. The depth of nanocrystalline (NC) layers was several $\mu \mathrm{m}$. The NC layers have extremely high hardness and were separated from the deformed structure regions just under the NC layers with sharp boundaries. By annealing, the NC layers show the substantially slow grain growth without recrystallization. These characteristics are similar to those observed in the specimens treated by ball milling, ball drop and particle impact deformation. Comparing ABSP and USSP at the similar peening condition, the produced volume of NC region in ABSP is larger than that in USSP.
\end{abstract}

(Received November 20, 2003; Accepted January 6, 2004)

Keywords: nanocrystallization, severe plastic deformation (SPD), air blast shot peening, ultrasonic shot peening, steel

\section{Introduction}

Nanocrystallization of bulk structural materials by severe plastic deformation (SPD) processes has been drawn strong attentions, since nanocrystalline (NC) materials (grain size smaller than $100 \mathrm{~nm}$ ) have superior mechanical and physical properties to those of coarse-grained counterparts. Various SPD processes have been proposed to produce the NC materials, such as ball milling $(\mathrm{BM}),{ }^{1-4)}$ ball drop deformation $(\mathrm{BD}){ }^{4,5)}$ particle impact deformation (PI), ${ }^{6}$ high pressure torsion, ${ }^{7}$ sliding wear ${ }^{8,9)}$ and shot peening. ${ }^{6,10-15)}$ Among these techniques, the shot peening has considerable importance since it is a popular process in industries and it can produce the nanostructured surface layer with a high productivity. From our previous BM, BD and PI experiments in steels, ${ }^{2-6)}$ it was found that the $\mathrm{NC}$ region has the following characteristics: 1$)$ extremely high hardness $(8 \sim 13 \mathrm{GPa}), 2)$ separated from deformed structure region with sharp boundary, 3) dissolution of cementite when it exists and 4) no recrystallization and slow grain growth by annealing.

In the present study, the surface nanocrystallization in various steels by shot peening (both air blast and ultrasonic) was investigated. The $\mathrm{NC}$ regions formed by these techniques were compared with those produced by BM, BD and PI.

\section{Experimental Procedures}

The materials used were $\mathrm{Fe}-0.03 \mathrm{C}$ (Fe-0.031C-0.052Si$0.054 \mathrm{Mn}$ in mass\% hereafter, ferrite structure), $\mathrm{Fe}-0.10 \mathrm{C}$ (Fe-0.099C-0.20Si-1.37Mn, martensite), Fe-0.80C (Fe$0.800 \mathrm{C}-0.20 \mathrm{Si}-1.33 \mathrm{Mn}$, either pearlite or spheroidite) and Fe-3.3Si (Fe-0.027C-3.29Si-0.01Mn, ferrite). Air blast shot peening (ABSP) was carried out using two different shot size, i.e. $\phi 0.05 \mathrm{~mm}$ (cast steel $(\mathrm{Fe}-1.0 \mathrm{C}, \mathrm{HV} 7.8 \mathrm{GPa}$ ), shot velocity: $190 \mathrm{~m} / \mathrm{s}$ ) and $\phi 0.3 \mathrm{~mm}$ (SUS304 (Fe-18Cr-8Ni, HV

\footnotetext{
*1 The Part of This Paper was Published in Japanese in J. Japan Inst. Metals 67 (2003) 689-695.

*2 This Paper was Presented at the Autumn Meeting of the Japan Institute of Metals, held in Sapporo, on October 12, 2003.
}

$5.3 \mathrm{GPa}$ ), shot velocity: $100 \mathrm{~m} / \mathrm{s}$ ). Coverage (the area fraction of specimen surface deformed by shots) larger than $50 \%$ was estimated by multiplying shot peening time by $\%$ coverage for one second measured at the state of $50 \%$ coverage. Ultrasonic shot peening (USSP) was performed using SUJ2 (Fe-1C-1.5Cr, HV 7.8 GPa) shot ( $\phi 0.4 \mathrm{~mm})$. In the USSP experiment, the shots were placed in the vibrating chamber (frequency: $20 \mathrm{kHz}$, amplitude: $90 \mu \mathrm{m}$ ), with which the shots were resonated. The projection distance was $10 \mathrm{~mm}$, and the shot velocity was less than $20 \mathrm{~m} / \mathrm{s}$. The details of conditions in ABSP and USSP were described in the previous paper. ${ }^{10)}$ Annealing of nanocrystallized specimens was carried out at $873 \mathrm{~K}$ for $3.6 \mathrm{ks}$ by sealing in a quartz tube under a pure Ar protective atmosphere. Specimens were characterized by SEM, TEM and Vickers microhardness tester. Specimens for SEM observations were etched by $5 \%$ Nital.

\section{Results and Discussions}

Figure 1 shows cross sectional SEM micrographs of various carbon steels processed by ABSP using $\phi 0.05 \mathrm{~mm}$ shot. From TEM observations, the equiaxed nanocrystals with grain size of several $10 \mathrm{~nm}$ were confirmed in the nanocrystalline (NC) surface layers. The NC layers have extremely high hardness and were separated from the adjacent deformed structure (DS) regions with sharp boundaries. ${ }^{6,10)}$ It is noted that the nanocrystallization occurs by ABSP irrespective of the carbon content or the initial structure of steels. In the $\mathrm{NC}$ region of $\mathrm{Fe}-0.80 \mathrm{C}$ pearlite (or spheroidite) steels shown in Figs. 1(c) (or (d)), cementite lamellae (or particles) are invisible in the $\mathrm{NC}$ region, indicating the dissolution of cementite took place. After annealing at $873 \mathrm{~K}$ for $3.6 \mathrm{ks}$, the NC regions still kept much finer structure than that of the DS regions. ${ }^{6,10)}$ These structures and the annealing behavior are similar to those observed in the specimens after BM, BD or PI. ${ }^{2-6)}$ The effect of coverage on the thickness of NC layer formed by ABSP was investigated. Figure 2 shows the cross sectional SEM micrographs of Fe-3.3Si steel processed by ABSP using $\phi$ $0.3 \mathrm{~mm}$ shot and annealed. The thickness of NC layer at the 

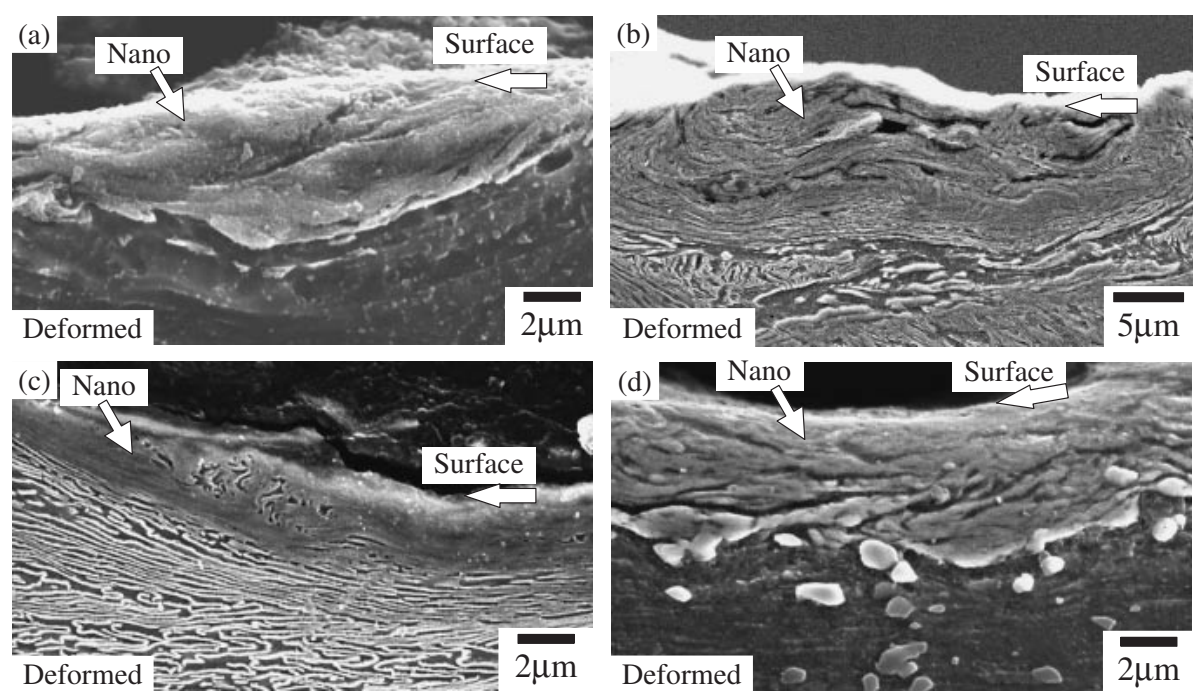

Fig. 1 SEM micrographs of NC layers formed in various steels after ABSP using $\phi 0.05 \mathrm{~mm}$ shot. (a) Fe- $0.03 \mathrm{C}$ (ferrite, $80 \%$ cold rolled, $1000 \%$ in coverage), (b) Fe- $0.10 \mathrm{C}$ (martensite, $6000 \%$ in coverage), (c) Fe- $0.80 \mathrm{C}$ (pearlite, $82 \%$ cold rolled, $1000 \%$ in coverage) and (d) $\mathrm{Fe}-0.80 \mathrm{C}$ (spheroidite, $84 \%$ cold rolled, $1000 \%$ in coverage).
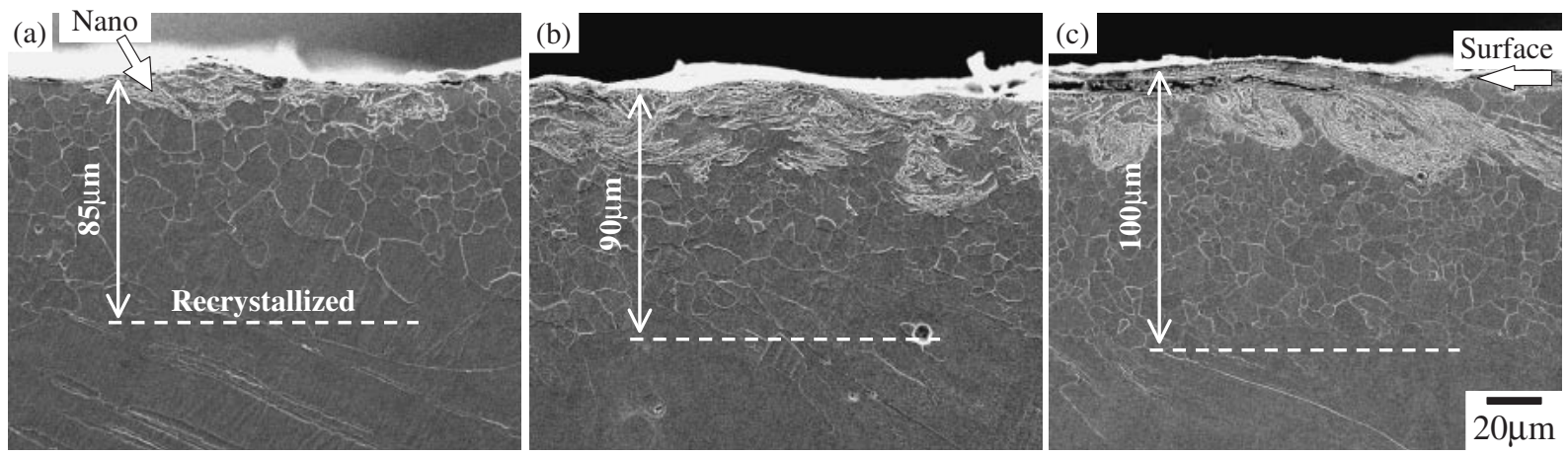

Fig. 2 The effect of coverage on the thickness of NC layer formed by ABSP. Fe-3.3Si steel was ABSPed using $\phi 0.3 \mathrm{~mm}$ shot and subsequent annealed. (a) $3000 \%$, (b) $10000 \%$ and (c) $30000 \%$ in coverage.
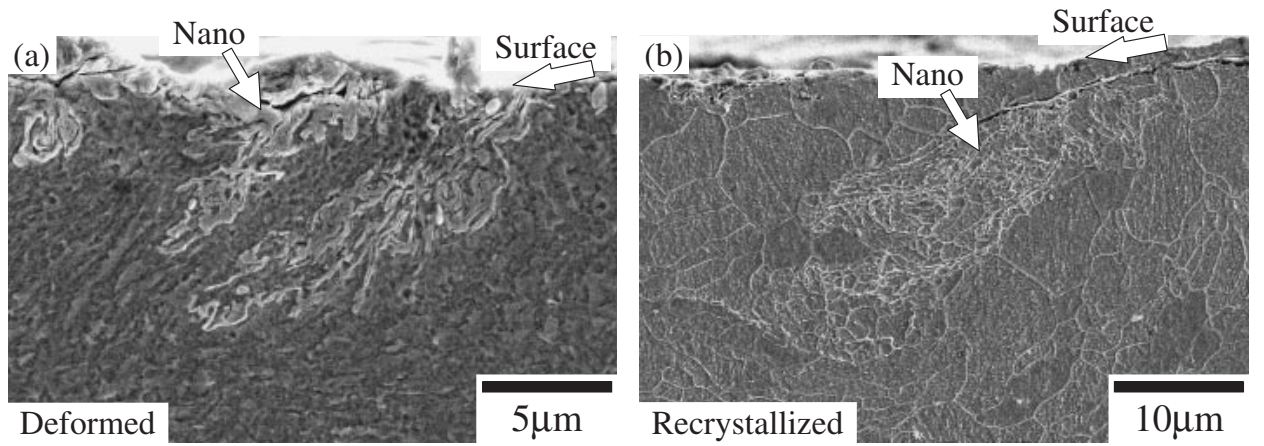

Fig. 3 SEM micrographs of Fe-0.03C specimen after (a) USSP (coverage: 36000\%, peening time: $1800 \mathrm{~s}$ ) and (b) subsequent annealing.

specimen surface increased with coverage. While, the thickness of the recrystallized structure (RS) layer increases slightly with coverage. The mean recrystallized grain size decreased from $6.9 \mu \mathrm{m}(3000 \%$ in coverage $)$ to $6.0 \mu \mathrm{m}$ $(10000 \%)$ and $5.4 \mu \mathrm{m}(30000 \%)$, indicates that the strain in these layers increased with coverage.

Figure 3 shows the typical microstructures of $\mathrm{Fe}-0.03 \mathrm{C}$ specimen after USSP and annealing. The formation of NC regions can be seen. These structures and the annealing behavior are similar to those observed in the specimens processed by ABSP. Figure 4 shows the comparison of the morphology of $\mathrm{NC}$ regions in $\mathrm{Fe}-0.80 \mathrm{C}$ spheroidite steel after APSP and USSP. Comparing these NC regions, the specimen processed by USSP showed the aggregated morphology and the NC regions tend to extend inwards from the surface instead of the forming layers like that observed in ABSP. The shot peening conditions of ABSP and USSP are summarized in Table 1. In ABSP, the shot velocity is around $100 \mathrm{~m} / \mathrm{s}$ and 

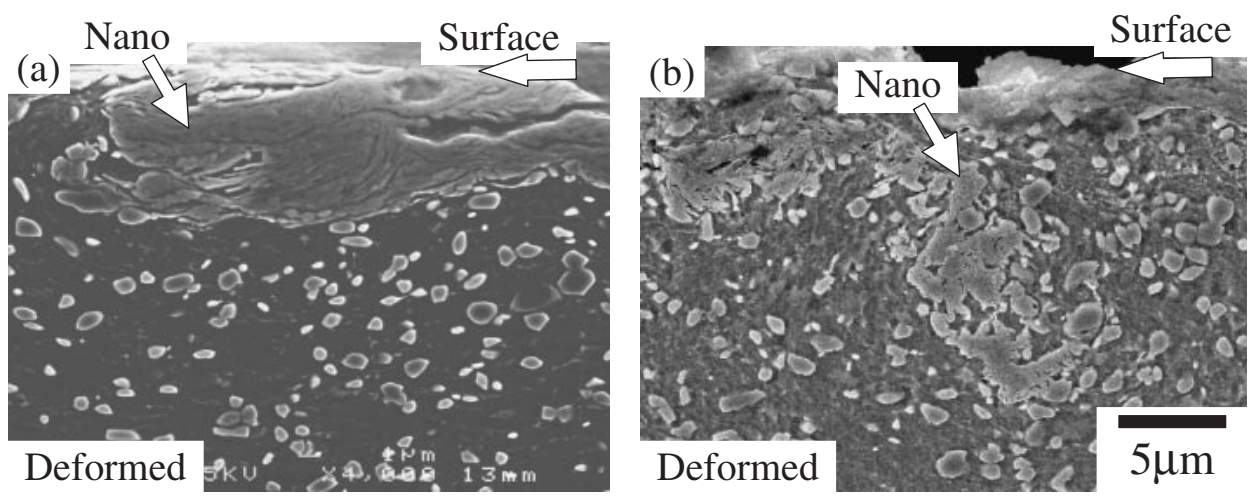

Fig. 4 Comparison of morphology of NC regions in Fe-0.80C spheroidite steel in (a) ABSP (shot: $\phi 0.05 \mathrm{~mm}, \mathrm{Fe}-1.0 \% \mathrm{C}$, shot velocity: $190 \mathrm{~m} / \mathrm{s}$, coverage: $6000 \%$, peening time: $60 \mathrm{~s}$ ) and (b) USSP (shot: $\phi 0.4 \mathrm{~mm}$, SUJ2, shot velocity: $<20 \mathrm{~m} / \mathrm{s}$, coverage: $108000 \%$, peening time: $5400 \mathrm{~s}$ ).

Table 1 Comparison of shot peening conditions of ABSP and USSP.

\begin{tabular}{|c|c|c|}
\hline Air blast shot peening & & Ultrasonic shot peening \\
\hline $\operatorname{Air}_{100,190 \mathrm{~m} / \mathrm{s}} \underset{6}{\rightarrow}=$ & $\begin{array}{l}\text { Schmatic } \\
\text { illustration } \\
\text { of } \\
\text { equipment }\end{array}$ & 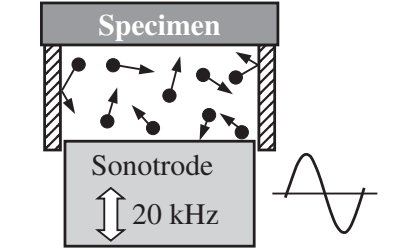 \\
\hline$\phi 0.05,0.3 \mathrm{~mm}$ & Shot size & $\phi 0.4 \mathrm{~mm}$ \\
\hline $\begin{array}{l}\text { High }(>100 \mathrm{~m} / \mathrm{s}) \\
\text { Velocity distribution - Small }\end{array}$ & Shot velocity & $\begin{array}{c}\text { Low }(<20 \mathrm{~m} / \mathrm{s}) \\
\text { Velocity distribution - Large }\end{array}$ \\
\hline Single-direction $\left(\sim 90^{\circ}\right)$ & $\begin{array}{l}\text { Impact } \\
\text { direction }\end{array}$ & Multi-direction \\
\hline $100,170 \% / \mathrm{s}$ & Coverage rate & $20 \% / \mathrm{s}$ \\
\hline
\end{tabular}

has a narrow distribution. On the other hand, in USSP the shot velocity is less than $20 \mathrm{~m} / \mathrm{s}$ and has a wide distribution. The impact direction of shot to specimen is almost perpendicular in ABSP and random in USSP. The impact energy of one shot in ABSP is much larger than that in USSP. The heat generation in specimen, therefore, is larger in ABSP than in USSP, and also the temperature gradient at the surface is larger in ABSP than in USSP. It is considered that the specimen temperature in USSP is rather constant through the depth since the coverage rate (per peening time) in USSP is smaller than that in ABSP. The deformation in USSP preferentially occurs around the grain boundaries and the $\mathrm{NC}$ regions tend to extend toward inside of the specimens. While, in the ABSP the temperature gradient at the surface is large and the deformation preferentially occurs parallel to the specimen surface and results in the layered morphology. Figure 5 shows the cross sectional SEM micrographs of Fe3.3Si steel after APSP and USSP. The produced volume of $\mathrm{NC}$ regions in ABSP is larger than that in USSP, even though the coverage in ABSP is about $80 \%$ of that in USSP. As are shown in Fig. 5, the recrystallized grain is $5.4 \mu \mathrm{m}$ in ABSP and $4.9 \mu \mathrm{m}$ size in USSP. The thickness of recrystallized layer is $100 \mu \mathrm{m}$ in ABSP and $35 \mu \mathrm{m}$ in USSP. These results indicate that a larger strain is given at a thin surface layer in USSP than that in ABSP. This difference is due to the lower surface temperature in USSP than in ABSP since the impact energy of one shot in USSP is much smaller than that in ABSP.

Lu et al. ${ }^{13-15)}$ have reported the surface nanocrystallization in various steels by USSP. In their experiments, the surface $\mathrm{NC}$ (grain size of about $10 \mathrm{~nm}$ ) layer was formed by USSP $(50 \mathrm{~Hz}, \phi 8 \mathrm{~mm}$ shot, $1.8 \mathrm{ks}$ of peening time). They reported that the grain size continuously decreased toward the surface and there is no discontinuous change in structure. The sharp boundaries along the $\mathrm{NC}$ region observed in the present study were not realized. They might overlook the boundaries between NC and DS regions since the area they observed by TEM is much smaller than ours. The differences are caused by the experimental conditions.

\section{Conclusions}

The NC layers with several $\mu \mathrm{m}$ thick were successfully produced in various steels by both ABSP and USSP. The NC layers have extremely high hardness and were separated with sharp boundaries from the adjacent DS regions. By annealing, the NC layers show the substantially slow grain growth without recrystallization. These characteristics are similar to those observed the specimens after BM, BD and PI. Comparing ABSP and USSP at the same coverage, the 

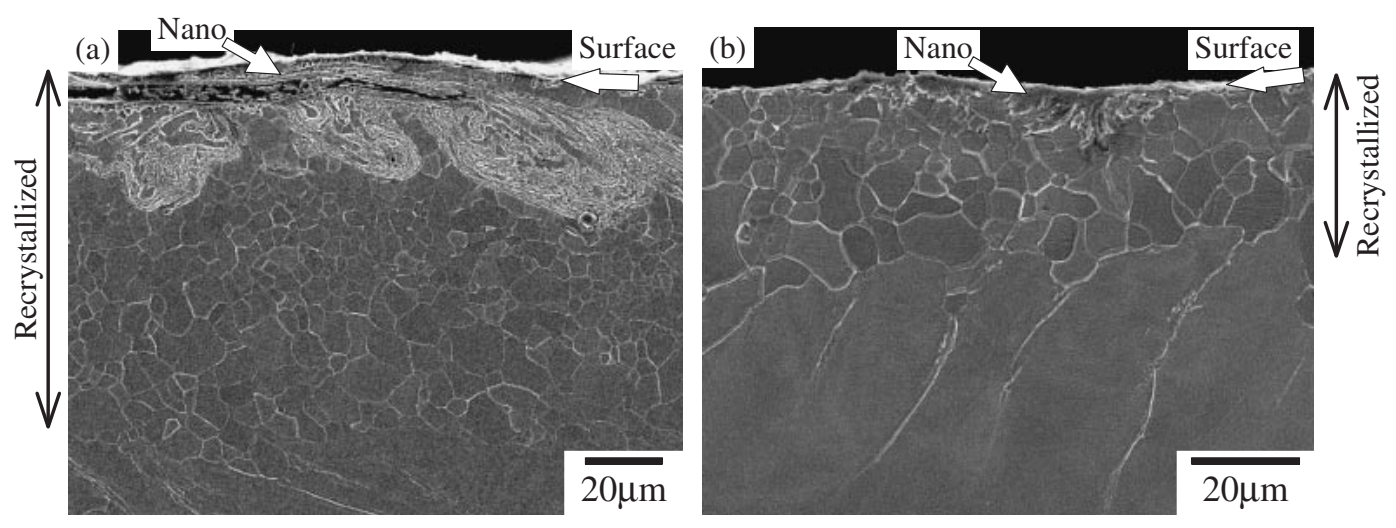

Fig. 5 SEM micrographs of Fe-3.3Si steel shot-peened and annealed. (a) ABSP (shot: $\phi 0.3 \mathrm{~mm}$, SUS304, shot velocity: $100 \mathrm{~m} / \mathrm{s}$, coverage: $30000 \%$, peening time: $180 \mathrm{~s}$ ) and (b) USSP (shot: $\phi 0.4 \mathrm{~mm}$, SUJ2, shot velocity: $<20 \mathrm{~m} / \mathrm{s}$, coverage: $36000 \%$, peening time: $1800 \mathrm{~s})$.

produced volume of $\mathrm{NC}$ region is larger in ABSP than in USSP. The DS region is thicker and the strain is smaller in ABSP than in USSP.

\section{Acknowledgments}

This study is financially supported in part by the Grant-inAid by the Japan Society for the Promotion of Science (No. 14205103) and the ISIJ Research Promotion Grant by the Iron and Steel Institute of Japan. Authors are grateful to TOYO SEIKO Co., Ltd. for applying USSP.

\section{REFERENCES}

1) C. H. Moelle and H. J. Fecht: NanoStructured Mater. 6 (1995) 421-424.

2) J. Yin, M. Umemoto, Z. G. Liu and K. Tsuchiya: ISIJ Int. 41 (2001) 1389-1396.

3) Y. Xu, M. Umemoto and K. Tsuchiya: Mater. Trans. 43 (2002) 22052212.

4) Y. Todaka, M. Umemoto and K. Tsuchiya: ISIJ Int. 42 (2002) 1429_
1436.

5) M. Umemoto, B. Huang, K. Tsuchiya and N. Suzuki: Scr. Mater. 46 (2002) 383-388.

6) M. Umemoto, Y. Todaka and K. Tsuchiya: Mater. Trans. 44 (2003) 1488-1493.

7) R. Z. Valiev, Y. V. Ivanisenko, E. F. Rauch and B. Baudelet: Acta Mater. 44 (1996) 4705-4712.

8) P. Heilmann, W. A. T. Clark and D. A. Rigney: Acta Metall. 31 (1983) 1293-1305.

9) D. A. Hughes, D. B. Dawson, J. S. Korellis and L. I. Weingarten: Wear 181-183 (1995) 458-468.

10) Y. Todaka, M. Umemoto, Y. Watanabe and K. Tsuchiya: J. Japan Inst. Metals 67 (2003) 689-695.

11) I. Altenberger, B. Scholtes, U. Martin and H. Oettel: Mater. Sci. Eng. A 264 (1999) 1-16.

12) X. Y. Wang and D. Y. Li: Wear 255 (2003) 836-845.

13) N. R. Tao, Z. B. Wang, W. P. Tong, M. L. Sui, J. Lu and K. Lu: Acta Mater. 50 (2002) 4603-4616.

14) G. Liu, S. C. Wang, X. F. Lou, J. Lu and K. Lu: Scr. Mater. 44 (2001) 1791-1795.

15) H. W. Zhang, Z. K. Hei, G. Liu, J. Lu and K. Lu: Acta Mater. 51 (2003) 1871-1881. 